\title{
Extreme events in the context of climate change
}

\author{
Sarah Perkins-Kirkpatrick ${ }^{a, b, c}$ and Andy Pitmana,b \\ a Climate Change Research Centre, UNSW Sydney, Australia \\ b Australian Research Council Centre of Excellence for Climate Extremes, UNSW Sydney \\ c Corresponding author: sarah.kirkpatrick@unsw.edu.au
}

\section{Article history}

Publication date: December 2018

Citation: Perkins-Kirkpatrick S, Pitman A. Extreme events in the context of climate change. Public Health Res Pract. 2018;28(4):e2841825. https://doi. org/10.17061/phrp2841825

\section{Key points}

- An increase in heatwaves is already occurring and will continue to worsen as anthropogenic climate change increases

- It is not clear how droughts and extreme rainfall events will change in the future

- We need to focus on building resilience to deal with the future effects of extreme events. Not doing so will ensure disastrous future impacts that we cannot currently fathom

\section{Abstract}

By definition, extreme events are rare. Socio-economic and human systems have not experienced adverse extreme events frequently enough to develop resilience, whether this be physical, economical or structural. Humans are vulnerable to extreme events because of our physiology and because we build thresholds into our socio-economic and human health systems. When these thresholds are exceeded the consequences can be devastating. This perspective will discuss changes in heat, drought and heavy rainfall extremes in the context of climate change.

\section{Defining climate extremes}

Our climate is changing as a consequence of human-induced greenhouse gas (GHG) emissions. ${ }^{1}$ Climate is typically defined as the average of 30 years of weather. At least initially, projected changes, on timescales of 30 years or longer, are likely to occur slowly enough so that many socio-economic and human systems can adapt. We are familiar with weather extremes such as heatwaves, storms, frost and extreme wind. To contemplate extreme events in the context of climate change requires a change in thinking from 'how might the Earth warm' to 'how will extreme events be expressed in a warmer climate'. When we look at how extreme events are changing, any sense of security we might have, based on a smooth, long-term temperature trend, evaporates.

Extreme events occur on meteorological to interannual timescales, from minutes to decades. They are governed on shorter timescales by prevailing weather systems and on longer timescales by modes of climate variability acting on the background state, with the background state changing because of rising GHG concentrations. The importance of specific weather systems and modes of variability is endemic to individual regions and to the extreme event of interest, so we cannot easily judge how climate change will be expressed in terms of extreme events in a particular region. Given this challenge, combined with the importance of providing advice to planners and policy makers, it is not surprising that understanding how extreme events are being affected by climate change is a high priority. ${ }^{2}$ 


\section{Heatwaves}

In a stationary climate, we expect the occurrences and intensity of temperature extremes to remain largely unchanged over time. A 1-in-50-year heatwave would occur on average once every 50 years, but may occur more or less often in a shorter time window, depending on what cycles of climate variability and weather systems eventuate. Because of GHG emissions, however, the global temperature has risen by about $1^{\circ} \mathrm{C}$ since $1860 .{ }^{1}$ This warming has led to a 'new normal' climate ${ }^{3}$, in which heat events that were once considered extreme are becoming more common.

As shown in Figure 1, a small increase in average temperatures can lead to large changes in the frequency of extreme heat events. Critically, unprecedented heat events emerge at the upper tail (Figure 1, far right), which would not have occurred in the original climate. This may be further exacerbated if temperature variability also increases; that is, the distribution becomes wider as well as shifting towards warmer conditions. Increases in extreme heat events are not theoretical; heatwaves have already worsened across the world. ${ }^{4}$ If health or other socio-economic systems have resilience to these 'novel' climates it is by luck, not by good planning, as we have not planned for events that historically did not exist.

It is important to recognise that heatwaves can change in intensity, frequency and duration; for example, a heatwave that may once have lasted 3 days and now lasts 10 days is both extreme and likely catastrophic. Moreover, extensive analysis has found a clear human signal behind recent heatwaves ${ }^{5}$, including those occurring on state ${ }^{6}$ and national ${ }^{7}$ levels in Australia. Locally, extreme heat records outnumber their cooler counterparts 12 to 1.8 During the 2017 Australian summer, Moree in northern New South Wales recorded 50 days higher than $35^{\circ} \mathrm{C}$, blitzing the previous record of 17 days This is well beyond predictions made within the climate community and highlights how a change of approximately $1^{\circ} \mathrm{C}$ in global mean temperature can translate into extreme events that are affecting us now.

Figure 1. Effect of warming on the probability of extreme events ${ }^{9}$

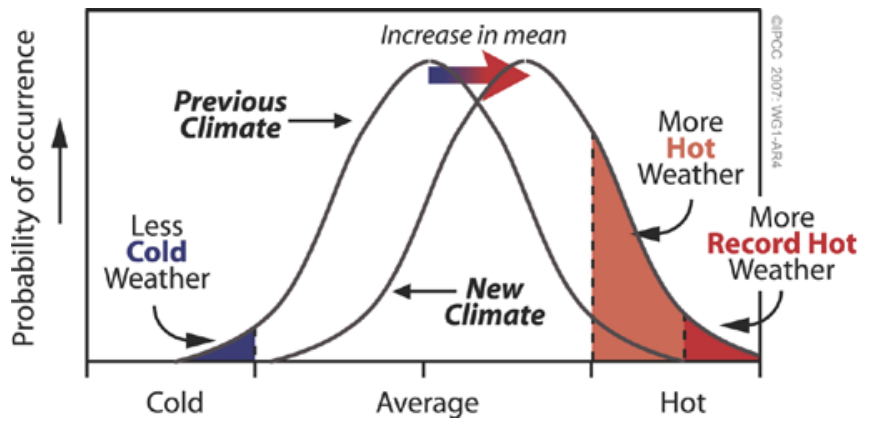

Unfortunately, the future of extreme heat does not look good for humans. We have already seen remarkable changes in extreme heat events with $1^{\circ} \mathrm{C}$ global warming; current projections estimate the planet will warm by 2.5-5. $8^{\circ} \mathrm{C}$ by 2100 under a business-as-usual scenario. Across Europe, approximately 100 extra heatwave days are projected to occur under these conditions ${ }^{10}$ with an extra 10-50 across Australia. ${ }^{11}$ The unprecedented heatwaves across Europe in 2003, Russia in 2010 and the US in 1980 will occur commonly by the middle of this century. ${ }^{12}$ Some regions such as the Arabian Peninsula may be uninhabitable by $2100 .^{13}$

\section{Droughts}

Droughts, largely characterised by long periods of very low rainfall, are primarily driven by modes of climate variability, occurring on seasonal to yearly timescales. The El Niño/Southern Oscillation (ENSO) and the Indian Ocean Dipole (IOD) influence Australian droughts; prolonged and intense events are common during El Niño and positive IOD seasons. ${ }^{14}$ Indeed, a combination of El Niño and positive IODs have been responsible for some of Australia's worst droughts. ${ }^{14}$ Droughts are also associated with extreme heat; heatwaves exacerbate soil desiccation, which in turn increases heatwave intensity and duration. ${ }^{15}$

We do not really know what will happen with droughts in the future - they are complex expressions of changes in modes of variability, synoptic states, rainfall, vegetation and soil moisture. There is some evidence that the occurrence of El Niño events will increase ${ }^{16}$, but an increase in the intensity of the hydrological cycle ${ }^{1}$ and more efficient water use by plants due to elevated $\mathrm{CO}_{2}$ levels may help reduce the risk of some droughts in some regions. In short, it is not clear how droughts will change in the future, which is of course a cause for concern in itself.

\section{Extreme rainfall}

Heavy rainfall events can range from local thunderstorms to tropical cyclones, and intense rainfall can occur on scales of minutes to days. It can also include events such as Hurricane Harvey in the southern US in 2017, during which rain-bearing systems became 'blocked' and rain fell for a long time over one place. Hazards often occurring as a direct result of heavy rainfall include floods and landslides, which also affect human health. However, these hazards are also strongly dependent on the size, geology and population of the affected area, and the overall vulnerability. Across Australia, heavy rainfall events are influenced by climate variability in a similar way to droughts. El Niño is generally responsible for droughts, whereas La Niña bears a large influence on extreme rainfall with the opposite phases generally being active. 
Daily extreme rainfall events have increased during the past 60 years and will continue to do so as human influence on the climate increases. ${ }^{17}$ This is because a warmer atmosphere holds more moisture $\left(7 \% /{ }^{\circ} \mathrm{C}\right)$, so more is available when a rainfall event is triggered. However, at least locally, the waiting time for extreme rainfall events is projected to increase. ${ }^{18}$ This indicates that events will not occur as often, but this is by no means certain for all regions. Changes in storm tracks can move heavy precipitation away from a region, thereby reducing rainfall intensity. Changes in synoptic patterns can reduce moisture flowing into a region, or reduce local convection and rainfall intensity. In short, future rainfall intensities can change in complex ways, which makes planning difficult.

\section{The future of climate extremes}

Our lack of detailed knowledge about how extreme events will change in a warming climate poses challenges for the health community. Heatwaves kill more people in Australia than all other natural disasters combined. ${ }^{19}$ Extreme heat currently adversely affects people with chronic ailments or those who are less mobile, those who work outdoors with little access to airconditioned environments, young children and the elderly. These demographics may widen in the future. The mental health of our rural communities is at high risk during droughts. ${ }^{20}$ How much more stress can these communities take and how might this stress be reduced? Events associated with extreme rainfall and flash flooding can also kill, isolate communities from services and increase the incidence of waterborne diseases. ${ }^{21}$ In the longer term, frequent flooding can lead to other problems including refusal of insurance, major economic stresses on communities and increased debt, particularly if the population grows in these areas. How best to plan for the effects of higher-intensity events is by no means clear.

A valuable step would be for the climate community to provide robust regional-scale future estimates for how extreme events might change. What we know about future climates is reliant on climate models. Because of computational complexity and limits to high-performance computers, climate model simulations are rectangles of approximately $200 \times 200 \mathrm{~km}$ over the Earth's surface. This is far coarser than many extreme events. To properly account for the synoptic scale phenomena associated with most extreme events, climate models need to use spatial detail of something like $20 \times 20 \mathrm{~km}$, which is beyond the capacity of the most powerful computers available to climate science.
Understanding how high-impact climate events will change in the future would clearly be valuable for informing many sectors including health. Progress in this area is a priority for the climate science community, but we are at least a decade away from skilful predictions of how extremes will change locally. In the meantime, there are a few pointers that might help decision making. Firstly, heatwaves will get worse and we are likely to be underestimating how soon this will happen. Secondly, on average, convective rainfall is likely to become more intense. Thirdly, there will be shocks; Hurricane Harvey, the 2017 Moree heatwave, recent heatwaves in Europe, India and Pakistan, and major recent floods in Japan and South Asia all bear the fingerprint of human-induced climate change and were worse than anticipated. Often, catastrophic extremes are linked to poor decision making by humans, so we should not wait for important scientific gaps to be filled. We must analyse how extreme events have affected systems we care about. Imagine what they may be like if they are a few degrees hotter, last longer or come with $50 \%$ more rainfall; will they cope, or be completely changed under the extra, unprecedented stress? Can our human systems be built to be resilient to such events? Can we successfully improve public health resources to cope with an increased burden of extreme heat-related presentations? Or fortify public infrastructure to survive extreme rainfall? Or increase the vigilance of rural communities so they can cope with increased risks to mental health? Building this resilience to extremes is the best way to safeguard the population from the very real and serious implications of climate change for human health.

\section{Acknowledgements}

Australian Research Council grants (FT170100106 and CE170100023).

\section{Peer review and provenance}

Externally peer reviewed, commissioned.

\section{Competing interests}

None declared.

\section{Author contributions}

SP-K drafted the manuscript and AP provided constructive edits and revisions. 


\section{References}

1. Intergovernmental Panel on Climate Change. Climate change 2013: the physical science basis. Contribution of Working Group I to the fifth assessment report of the Intergovernmental Panel on Climate Change. Stocker TF, Qin D, Plattner GK, Tignor M, Allen SK, Boschung J, et al (eds). Cambridge UK: Cambridge University Press; 2013 [cited 2018 Oct 25]. Available from: www. climatechange2013.org/images/report/WG1AR5_ALL_ FINAL.pdf

2. Coumou D, Rahmstorf S. A decade of weather extremes. Nature Climate Change. 2012;491:6.

3. Lewis SC, King AD, Perkins-Kirkpatrick SE. Defining a new normal for extremes in a warming world. Bulletin of the American Meteorological Society. 2017;1139:51.

4. Perkins SE, Alexander LV, Nairn JR. Increasing frequency, intensity and duration of observed global heatwaves and warm spells. Geophysical Research Letters. 2012;L20714.

5. Herring SC, Hoell A, Hoerling MP, Kossin JP, Schreck CJ, Stott PA, editors. Explaining extreme events of 2015 from a climate perspective. Bulletin of the American Meteorological Society, 2015;S1:S145.

6. Lewis SC, Karoly DJ. Anthropogenic contributions to Australia's record summer temperatures of 2013. Geophysical Research Letters. 2013;3705:9

7. Perkins SE, Lewis SC, King AD, Alexander LV. Increased simulated risk of the hot Australian summer of 2012/13 due to anthropogenic activity as measured by heat wave frequency and intensity. Bulletin of the American Meteorological Society. 2014;S34.

8. Lewis SC, King AD. Dramatically increased rate of observed hot record breaking in recent Australian temperatures. Geophysical Research Letters. 2015;7776:84.

9. Intergovernmental Panel on Climate Change. Climate Change 2007: the physical science basis. Contribution of Working Group I to the fourth assessment report of the Intergovernmental Panel on Climate Change. Solomon S, Qin D, Manning M, Chen Z, Marquis M, Averyt K, et al, editors. Cambridge UK: Cambridge University Press; 2007 [cited 2018 Oct 25]. Available from: www.ipcc.ch/ pdf/assessment-report/ar4/wg1/ar4_wg1_full_report.pdf

10. Schoetter R, Cattiaux J, Douville H. Changes of western European heat wave characteristics projected by the CMIP5 ensemble. Climate Dynamics. 2015;1601:16.
11. Cowan T, Purich A, Perkins S, Pezza A, Boschat G, Sadler K. More frequent, longer, and hotter heat waves for Australia in the twenty-first century. Journal of Climate. $2014 ; 5851: 71$

12. Russo S, Dosio A, Graversen RG, Sillmann J, Carrao H, Dunbar MB, et al. Magnitude of extreme heat waves in present climate and their projection in a warming world. Journal Geophysical Research: Atmospheres. 2014; $12500: 12$

13. Pal JS, Eltahir EA. Future temperature in southwest Asia projected to exceed a threshold for human adaptability. Nature Climate Change. 2016;197:200.

14. Ummenhofer CC, England MH, Mclntosh PC, Meyers GA, Pook MJ, Risbey JS, et al. What causes southeast Australia's worst droughts? Geophysical Research Letters. 2009:L04706.

15. Miralles DG, Teuling AJ, Van Heerwaarden CC, de Arellano JVG. Mega-heatwave temperatures due to combined soil desiccation and atmospheric heat accumulation. Nature Geoscience. 2014;345:9.

16. Cai W, Borlace S, Lengaigne M, Van Rensch P, Collins M, Vecchi $G$, et al. Increasing frequency of extreme El Niño events due to greenhouse warming. Nature Climate Change. 2014;111:16.

17. Donat MG, Lowry AL, Alexander LV, O'Gorman PA, Maher N. More extreme precipitation in the world's dry and wet regions. Nature Climate Change. 2016;508:13

18. CSIRO and Bureau of Meteorology (Australia). Climate change in Australia: information for Australia's natural resource management regions: technical report; 2015 [cited 2018 Sep 28]. Available from: www. climatechangeinaustralia.gov.au/media/ccia/2.1.6/cms_ page_media/168/CCIA_2015_NRM_TechnicalReport_ WEB.pdf

19. Coates L, Haynes K, O’Brien J, McAneney J, de Oliveira FD. Exploring 167 years of vulnerability: an examination of extreme heat events in Australia 18442010. Environmental Science \& Policy. 2014;33:44.

20. Blashki G, McMichael T, Karoly D. Climate change and primary health care. Aust Fam Physician. 2007;986-9.

21. Auld H, Maclver D, Klaassen J. Heavy rainfall and waterborne disease outbreaks: the Walkerton example. J Toxicol Environ Health, Part A. 2004;1879-87.

\section{Copyright: (c)}

(C) 2018 Perkins-Kirkpatrick and Pitman. This article is licensed under the Creative Commons Attribution-NonCommercial-ShareAlike 4.0 International Licence, which allows others to redistribute, adapt and share this work non-commercially provided they attribute the work and any adapted version of it is distributed under the same Creative Commons licence terms. See: www.creativecommons.org/licenses/by-nc-sa/4.0/ 